\title{
Continuous Improvement for Manufacturing Techniques: Thin Film Coating and More
}

Qing Hao

Received date: 15 January 2021; Accepted date: 2 February 2021.

Article type: Editorial article.

The rapid development of many applications heavily depends on cost-effective techniques for mass production. Along this line, advanced techniques such as molecular-beam epitaxy (MBE) can provide excellent controls of atomic structures but are mostly restricted for fundamental research due to the extremely high cost and low productivity. For industrial applications, conventional methods such as hydrothermal coating are still emphasized and there is still plenty of room for potential improvements. This issue provides a list of examples for such efforts.

To fabricate supercapacitors for energy-storage applications, ${ }^{[1]}$ employed a chemical spray method to grow nickel cobalt oxide $\left(\mathrm{NiCo}_{2} \mathrm{O}_{4}\right)$ thin films on a conducting glass substrate. A supercapacitance of $777 \mathrm{~F} / \mathrm{g}$ at scan rate $5 \mathrm{mV} / \mathrm{s}$ was achieved with such a simple method. For photoelectrochemical or photoactivity applications, Rahane et al. ${ }^{[2]}$ used the facile hot injection method to produce $\mathrm{CdS}$ nanocrystals. The same technique was also employed by Barma et al..$^{[3]}$ to synthesize CdSe nanocrystals. Borate et al.$^{[4]}$ employed a single-step electrodeposition technique and annealing to deposit CZTS thin films on Mo coated corning glass substrate. These coating techniques have been widely studied for thin-film devices deposited on arbitrary substrates. The significant advantages in the production rate and manufacturing cost make these coating techniques well suitable for many large-scale applications.

As a cost-effective approach to fabricate film-based thermoelectric devices, the electrochemically deposition was used by Gite et al. ${ }^{[5]}$ to prepare PbTe films on a pure copper substrate at room temperature. Such deposition processes have been widely studied for the fabrication of thermoelectric devices, particularly on flexible substrates. In the pursuit of a lower thermal conductivity for better thermoelectric performance, these nanocrystalline samples are preferred

Department of Aerospace and Mechanical Engineering, University of Arizona, Tucson, AZ 85721-0119.

Email: qinghao@email.arizona.edu when bulk-like electrical conductivities can still be preserved. One challenge is how to minimize the detrimental oxidation during the synthesis process, which should be addressed in future studies.

Other than synthesis techniques, a few other important topics are also covered in this issue. Pan et al. ${ }^{[6]}$ reviewed the recent progresses on catalytic pyrolysis to process waste plastics (e.g., polyethylene, polyvinyl chloride, polypropylene, polystyrene) and petroleum sludge (i.e., main residual from the petroleum industry). Mu et al. ${ }^{[7]}$ developed a process to transfer lignin into bio-oil with excellent lubrication properties. Zhou et al. ${ }^{[8]}$ employed the solution-cast method to add P[MPEGMA-IL] and graphene into PLA/PCL blends to change the dielectric properties. As one traditional topic, Ding et al. ${ }^{[9]}$ studied the impact of the Ag content on the properties of widely used Sn-Bi solders.

In summary, several papers in this issue shows future research opportunities to further advance the manufacturing techniques for various applications. More fundamental studies on the material synthesis (e.g., molecular dynamics simulation, in-situ measurements during the synthesis) should be carried out to improve such techniques that provide a cheap alternative for producing the desired thin films and devices. The environmental issues, such as how to handle the industrial waste, should also receive more attention.

\section{References}

[1] Deokate, ES Mater. Manuf., 2021, 16-19. doi: 10.30919/esmm5f938.

[2] G. K. Rahane, S. B. Jathar, S. R. Rondiya, Y. A. Jadhav, S. V. Barma etal, ES Mater. Manuf., 2021, 57-64. doi: 10.30919/esmm5f1041.

[3] S. V. Barma, S. R. Rondiya, Y. A. Jadhav, S. B. Jathar, G. K. Rahane, A. Rokade, R. W. Cross, M. P. Nasane, V. Jadkar, N. Y. Dzade and S. R. Jadkar, ES Mater. Manuf., 2021, 50-56. doi: 10.30919/esmm5f1040. 
[4] H. Borate, A. Bhorde, A. Waghmare, S. Nair, S. Pandharkar, A. Punde, P. Shinde, P. Vairale, V. Jadkar, R. Waykar, S. Rondiya, Y. Hase, R. Aher, N. Patil, M. Prasad and S. Jadkar, ES Mater. Manuf., 2021, 30-39. doi: 10.30919/esmm5f934.

[5] A. B. Gite, B. M. Palve, V. B. Gaikwad, S. D. Shinde, G. H. Jain and H. M. Pathan, ES Mater. Manuf., 2021, 40-49. doi: 10.30919/esmm5f932.

[6] D. Pan, F. Su, H. Liu, C. Liu, A. Umar, L. Castañeda, H. Algadi, C. Wang and Z. Guo, ES Mater. Manuf., 2021, 3-15. doi: 10.30919/esmm5f415.

[7] L. Mu, Y. Dong, L. Li, X. Gu and Y. Shi, ES Mater. Manuf., 2021, 72-80. doi: 10.30919/esmm5f1146.

[8] Y. Zhou, P. Wang, G. Ruan, P. Xu and Y. Ding, ES Mater. Manuf., 2021, 20-29. doi: 10.30919/esmm5f928.

[9] Y. Ding, F. Wang, Y. Li and K. Wang, ES Mater. Manuf., 2021, 65-71. doi: 10.30919/esmm5f1045.

Publisher's Note Engineered Science Publisher remains neutral with regard to jurisdictional claims in published maps and institutional affiliations.

\section{Author information}

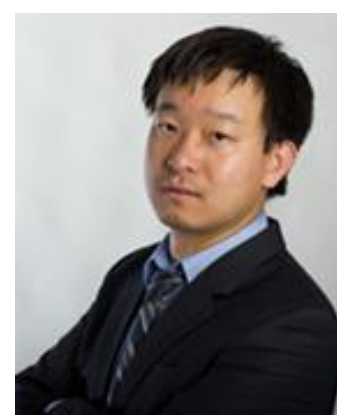

Qing Hao is an Associate Professor of Department of Aerospace and Mechanical Engineering at the University of Arizona. His research focuses on nanoscale energy transport in materials and electronic devices, including thermoelectrics, high-power electronics, and $2 D$ materials. He received the 2008 R\&D 100 Award as a team member for thermoelectrics research, 2015 AFOSR YIP Award for graphene studies, and 2017 NSF CAREER Award for thermal studies of grain boundaries. He was selected as the inaugural class of the Craig M. Berge Dean's Fellows in 2020. 